\title{
Synthesis and characterization of thermally stable pink-red inorganic pig- ment for digital color
}

\author{
Won-Jun Lee,**, Hae-Jin Hwang**, Jin-Ho Kim*, Woo-Suk Cho* and Kyu-Sung Han*,† \\ *Icheon Branch, Korea Institute of Ceramic Engineering \& Technology (KICET), Icheon 467-843, Korea \\ **School of Material Science and Engineering, Inha University, Incheon 402-751, Korea \\ (Received June 30, 2014) \\ (Revised July 9, 2014) \\ (Accepted July 18, 2014)
}

\begin{abstract}
Digital ink-jet printing system has many advantages such as fast and fine printing of various images, high efficiency and low cost process. Generally digital ink-jet printing requires ceramic pigments of cyan, magenta, yellow and black with thermal and glaze stability above $1000^{\circ} \mathrm{C}$ for the application of porcelain product design. In this study, pink-red colored $\mathrm{CaO}-\mathrm{SnO}_{2}-\mathrm{Cr}_{2} \mathrm{O}_{3}-\mathrm{SiO}_{2}$ pigment was synthesized using solid state reaction. The synthesis conditions of $\mathrm{Ca}(\mathrm{Cr}, \mathrm{Sn}) \mathrm{SiO}{ }_{5}$ pigment such as annealing temperature, amount of mineralizer and non-stoichiometric composition were optimized. Crystal structure and morphology of the obtained $\mathrm{Ca}(\mathrm{Cr}, \mathrm{Sn}) \mathrm{SiO}_{5}$ pigment were analyzed using XRD, SEM, PSA, FT-IR and effect of $\mathrm{Cr}$ substitution on the pigment color was analyzed using Uv-vis. spectrophotometer and CIE L*a*b* measurement.
\end{abstract}

Key words Ceramic pigment, Ink-jet printing, $\mathrm{Ca}(\mathrm{Cr}, \mathrm{Sn}) \mathrm{SiO}_{5}$, Solid state reaction

\section{디지털 컬러용 pink-red 고온발색 무기안료의 합성 및 특성평가}

이원준 ***, 황해진**, 김진호*, 조우석*, 한규성*,

*한국세라믹기술원 이천분원, 이천, 467-843

**인하대학교 신소재공학부, 인천, 402-751

(2014년 6월 30일 접수)

(2014년 7월 9일 심사완료)

(2014년 7월 18일 게재확정)

요 약 최근 각광받고 있는 디지털 프린팅을 이용한 디자인 기법은 세밀한 표현과 다양한 이미지 구현이 가능하고, 원 료의 낭비가 적어 효율성이 높은 장점을 가지고 있다. 디지털 프린팅 공정에서는 cyan, magenta, yellow, black이 기본적인 디지털 4 원색으로 사용되며, 도자제품에 적용되는 세라믹 안료의 경우 $1000^{\circ} \mathrm{C}$ 이상의 고온 소성이 가능하도록 우수한 열적, 유약 안정성과 발색 특성이 요구된다. 본 연구에서는 고상합성법을 이용하여 $\mathrm{CaO}-\mathrm{SnO}_{2}-\mathrm{Cr}_{2} \mathrm{O}_{3}-\mathrm{SiO}_{2}$ 조성의 pink-red 고온발 색 무기안료를 합성하였다. $\mathrm{Ca}(\mathrm{Sn}, \mathrm{Cr}) \mathrm{SiO}_{5}$ 세라믹 안료의 합성 조건에 따른 물성을 XRD, SEM, PSA, FT-IR를 이용하여 분 석하였고, $\mathrm{Cr}$ 치환량 변화가 $\mathrm{Ca}(\mathrm{Sn}, \mathrm{Cr}) \mathrm{SiO}_{5}$ 무기 안료의 발색 거동에 미치는 영향을 Uv-vis.와 $\mathrm{CIE}$ 표색계 값 $\left(\mathrm{L}^{*} \mathrm{a}^{*} \mathrm{~b}^{*}\right)$ 을 기 준으로 한 색도측정을 통해 관찰하였다.

\section{1. 서}

최근 생활수준의 향상 및 우수한 디자인에 대한 소비 자의 요구 증가와 함께 생활밀착형 제품인 생활식기, 타 일, 위생도기와 같은 도자제품에서도 다양한 컬러의 디 자인이 요구되고 있다. 도자제품에 컬러 디자인을 적용

\footnotetext{
Corresponding author

Tel: +82-31-645-1404

Fax: +82-31-645-1488

E-mail:kh389@kicet.re.kr
}

하기 위해 기존에는 주로 실크 프린팅과 전사기법을 사 용하였으나 다양한 색상 및 패턴 구현에 어려움이 있고 원료 낭비가 심하다는 문제점이 있어 왔다. 반면 잉크젯 프린팅과 레이저 프린팅과 같은 디지털 프린팅 공정은 디지털 신호에 의해 원하는 위치에 잉크가 토출되는 방 식으로 다양한 이미지 구현이 가능하며 원료의 낭비가 적어 효율성 높은 친환경적 공정이라는 장점을 가지고 있다 $[1,2]$. 디지털 프린팅 공정에서는 cyan, magenta, yellow, black의 컬러가 기본적인 디지털 4원색으로 사 용되며, 도자제품에 적용하기 위해서는 $1000^{\circ} \mathrm{C}$ 이상의 
고온 소성을 위해 우수한 열적 안정성을 가진 세라믹 안 료 개발이 필수적이다[2].

디지털 4원색 중 magenta 컬러는 기존에 $\mathrm{Au}$ 나 $\mathrm{Cd}$ 을 포함한 무기안료 입자가 이용되어 왔으나, 각각 높은 가 격과 환경규제 물질이라는 이유로 이들을 대체하는 새로 운 조성의 magenta 컬러 무기안료 입자 개발이 요구되 어 왔다[1-3]. 최근에는 pink-red를 발색하는 무기안료인 $\mathrm{CaO}-\mathrm{SnO}_{2}-\mathrm{SiO}_{2}-\mathrm{Cr}_{2} \mathrm{O}_{3}$ 조성이 $1300^{\circ} \mathrm{C}$ 까지 사용 가능한 적색 계열 안료의 대안으로 주목받고 있다[4, 5, 7].

본 연구에서는 고상합성법을 이용하여 pink-red 발색 $\mathrm{Ca}(\mathrm{Sn}, \mathrm{Cr}) \mathrm{SiO}_{5}$ 세라믹 안료를 제조하고 합성 조건에 따 른 발색 거동을 분석하였다 $[8,9]$. 최적 합성 조건을 확 립하기 위해 하소 온도 및 광화제의 첨가량을 최적화하 여 pink-red를 발색하는 $\mathrm{Ca}(\mathrm{Sn}, \mathrm{Cr}) \mathrm{SiO}_{5}$ (malayaite)의 성 장을 촉진시켰으며, $\mathrm{SnO}_{2}$ 를 비화학양론 조성비로 합성 하여 $\mathrm{Ca}(\mathrm{Sn}, \mathrm{Cr}) \mathrm{SiO}_{5}$ 무기안료의 합성 과정 중 malayaite 와 함께 생성되는 $\mathrm{SnO}_{2}$ (cassiterite)를 최소화하였다. 또 한 $\mathrm{Cr}$ 치환량에 따른 $\mathrm{Ca}(\mathrm{Sn}, \mathrm{Cr}) \mathrm{SiO}_{5}$ 세라믹 안료의 결 정 구조 및 발색 거동을 분석하였다.

\section{2. 실험방법}

\section{1. $\mathrm{Ca}(\mathrm{Sn}, \mathrm{Cr}) \mathrm{SiO}_{5}$ 무기안료의 합성}

고상합성법을 이용하여 pink-red를 발색하는 $\mathrm{Ca}(\mathrm{Sn}$, $\mathrm{Cr}) \mathrm{SiO}_{5}$ 무기안료를 합성하기 위해서 출발 물질로 $1 \mathrm{~mol}$ 의 $\mathrm{CaO}$ (Calcium oxide, $98.0 \%$, JUNSEI) $0.6 \sim 1.0 \mathrm{~mol}$

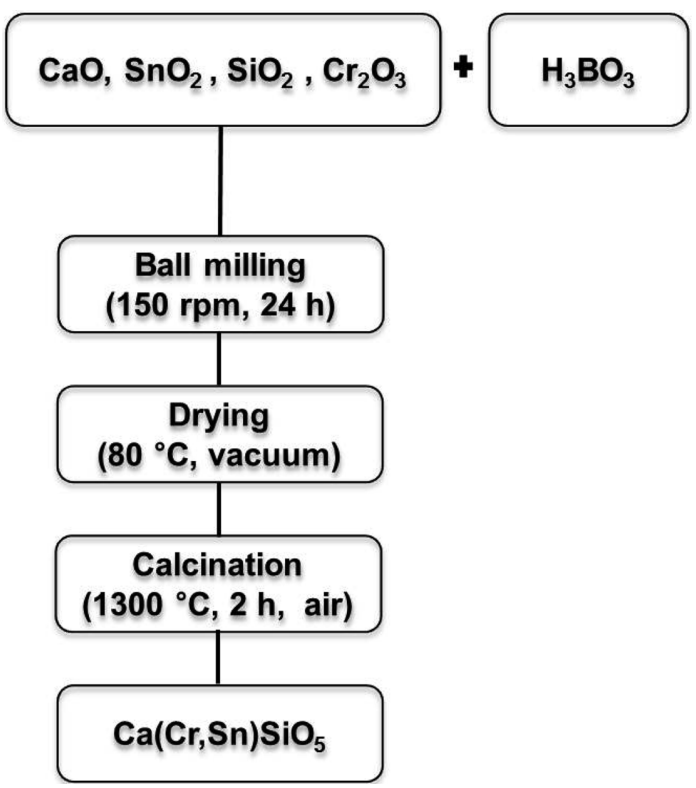

Fig. 1. Experimental procedure of $\mathrm{Ca}(\mathrm{Cr}, \mathrm{Sn}) \mathrm{SiO}_{5}$ synthesis using solid state reaction.
의 $\mathrm{SnO}_{2}$ (Tin oxide, Chemical Pure, JUNSEI), 1 mol 의 $\mathrm{SiO}_{2}$ (Silicon oxide, $99.0 \%$, SHOWA), $0.01 \sim 0.3 \mathrm{~mol}$ 의 $\mathrm{Cr}_{2} \mathrm{O}_{3}$ (Chromium oxide, $98.5 \%$, SAMCHUN)를 사용하 였다. 결정 성장을 촉진시키거나 치환물의 고용화를 유 도하기 위한 광화제로는 $\mathrm{H}_{3} \mathrm{BO}_{3}$ (Boric acid, $99.5 \%$, $\mathrm{SAMCHUN})$ 을 사용하였다. 각 분말은 직경 $3 \mathrm{~mm}$ 의 알 루미나 볼과 함께 에탄올과 혼합하여 24시간 동안 밀링한 후 $80^{\circ} \mathrm{C}$ 에서 완전히 건조하였다. 하소 공정은 air 분위기 로 $900^{\circ} \mathrm{C}$ 까지 $5^{\circ} \mathrm{C} / \mathrm{min}$ 로 승온시킨 후, $1100^{\circ} \mathrm{C}, 1300^{\circ} \mathrm{C}$, $1500^{\circ} \mathrm{C}$ 의 목표 온도까지 $3^{\circ} \mathrm{C} / \mathrm{min}$ 로 승온시켜, 2 시간 유 지하였다. Fig. 1에 고상합성법을 이용한 $\mathrm{Ca}(\mathrm{Sn}, \mathrm{Cr}) \mathrm{SiO}_{5}$ 안료의 합성 과정의 모식도를 나타내었다.

\section{2. $\mathrm{Ca}(\mathrm{Sn}, \mathrm{Cr}) \mathrm{SiO}_{5}$ 무기안료의 특성 분석}

합성된 세라믹 안료의 결정구조를 X-Ray diffractometer (XRD, Rigaku, D/2500VL/PC)와 FT-IR(Nicolet 6700, Thermo scientific)을 이용하여 분석하였으며, 안료 입자 의 크기와 형상 분석을 위해 레이저 회절 방식의 입도 분석기(LA950-V2, HORIBA)와 Field emission scanning electron microscope(FE-SEM, JEOL, JSM-6390)을 사용 하였다. 또한 Uv-vis. spectrophotometer(Agilent, Cary100) 를 이용하여 발색 거동을 분석하였으며, 색도 변화를 관 찰하기 위해 Spectrophotometer(CM-700D, Konica)를 이용하여 국제조명위원회(CIE: Commission international I'eclairage) 표색계의 값 $\left(\mathrm{L}^{*} \mathrm{a}^{*} \mathrm{~b}^{*}\right)$ 을 측정하였다.

\section{3. 결과 및 고찰}

Fig. 2는 고상합성법을 이용하여 $\mathrm{CaO}, \mathrm{SnO}_{2}, \mathrm{SiO}_{5}$ 를 각각 $1 \mathrm{~mol}$ 씩 혼합한 분말의 하소 온도에 따른 $\mathrm{XRD}$ 분 석 결과이다. Fig. $2(\mathrm{a})$ 의 $900^{\circ} \mathrm{C}$ 에서 하소한 분말의 경 우 낮은 하소 온도로 인하여 아직 출발 물질들이 서로 반응하지 못해 $\mathrm{CaO}, \mathrm{SnO}_{2}, \mathrm{SiO}_{2}$ 에 해당하는 피크가 확 인되었다. Fig. 2(b)의 $1100^{\circ} \mathrm{C}$ 에서 하소한 분말의 XRD 패턴에서는 $\mathrm{CaSnO}_{3}$ 와 $\mathrm{SiO}_{2}$ 피크가 확인되었고, 이는 출 발 물질 중 $\mathrm{CaO}$ 와 $\mathrm{SnO}_{2}$ 가 먼저 반응하여 $\mathrm{CaSnO}_{3}$ 를 형 성한 것으로 판단된다. Fig. $2(\mathrm{c})$ 의 $1300^{\circ} \mathrm{C}$ 에서 하소된 무 기안료에서는 $\mathrm{CaSnSiO}_{5}$ 피크가 나타나기 시작하였으며 $\mathrm{SnO}_{2}$ 피크가 다소 높게 관찰되었다. $\mathrm{CaSnSiO}_{5}$ (malayaite) 는 titanate 구조로 이루어져 있고, $\mathrm{Cr}_{2} \mathrm{O}_{3}$ 가 고용될 경우 $\mathrm{Cr}(\mathrm{III})$ 와 $\mathrm{Cr}(\mathrm{IV})$ 가 혼재되어 존재하며, 특히 $\mathrm{Cr}(\mathrm{IV})$ 의 영향으로 짙은 pink-red 계열을 발색하는 것으로 알려져 있다. 열적 안정성이 우수하여 고온용 무기 안료로 사용 되기에 적합한 특성을 가진다. 반면, $\mathrm{SnO}_{2}$ (cassiterite)는 rutile 구조로 이루어져 있으며, 고온에서 생성되는 반응 
물이나 $\mathrm{Cr}(\mathrm{III})$ 의 영향으로 주로 purple, violet 계열로 발색하는 것으로 알려져 있다 $[5,10]$. 하소 온도가 $1500^{\circ} \mathrm{C}$ 까지 증가한 경우에는 Fig. 2(d)와 같이 $\mathrm{CaSnSiO}_{5}$ 피크 가 급격히 성장함을 확인할 수 있었다.

Fig. 3은 하소 온도에 따른 분말의 미세구조를 SEM으 로 분석한 결과이다. 하소 온도가 $900^{\circ} \mathrm{C}$ 일 경우에는

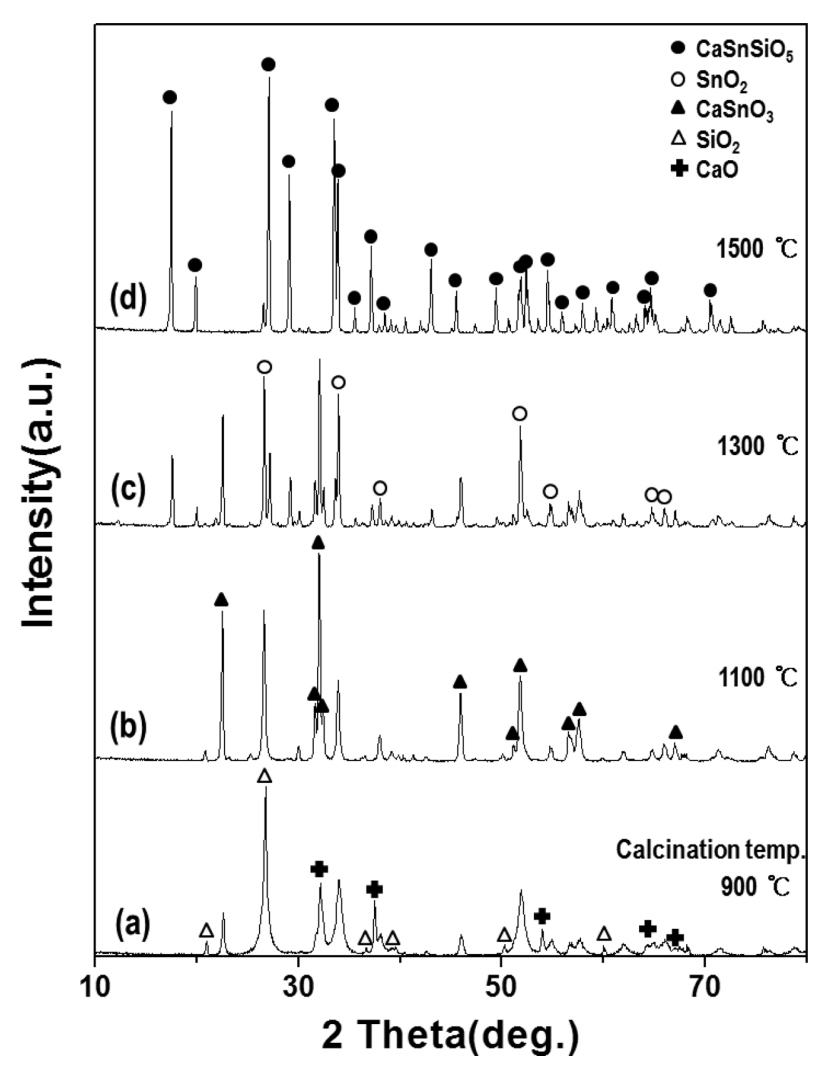

Fig. 2. XRD patterns of $\mathrm{CaSnSiO}_{5}$ calcined at different temperatures. (a) $900^{\circ} \mathrm{C}$, (b) $1100^{\circ} \mathrm{C}$, (c) $1300^{\circ} \mathrm{C}$, (d) $1500^{\circ} \mathrm{C}$.

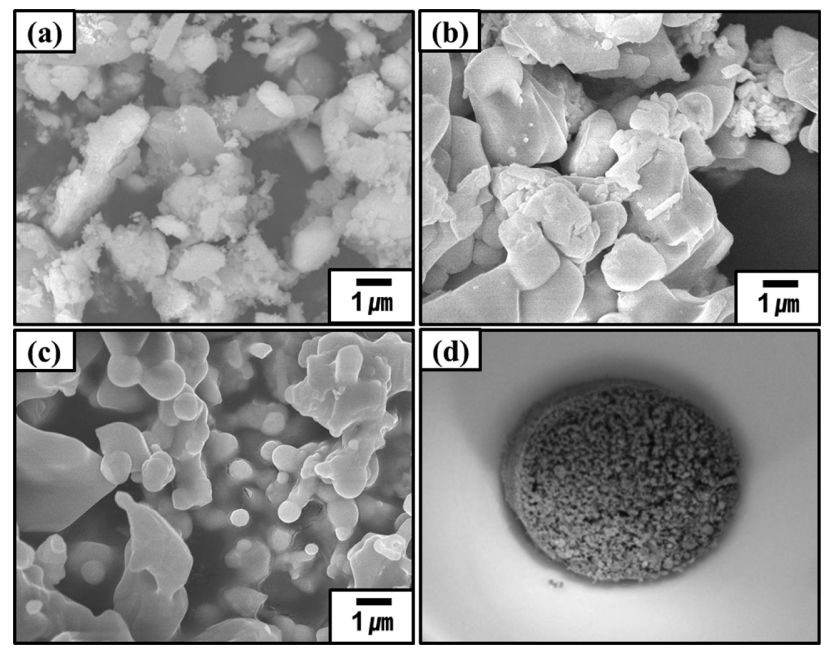

Fig. 3. SEM images of $\mathrm{CaSnSiO}_{5}$ calcined at (a) $900^{\circ} \mathrm{C}$, (b) $1100^{\circ} \mathrm{C}$, (c) $1300^{\circ} \mathrm{C}$ and (d) optical image of $\mathrm{CaSnSiO}_{5}$ calcined $1500^{\circ} \mathrm{C}$
Fig. 3(a)와 같이 낮은 열처리 온도로 인하여 출발 물질들 의 합성이 잘 이루어 지지 않아 여러 형태의 입자들이 혼 재되어있는 것을 확인할 수 있었고, Fig. $3(\mathrm{~b})$ 의 $1100^{\circ} \mathrm{C}$ 에 서 하소한 분말에서도 Fig. 3(a)와 유사한 형태의 입자들 이 응집되어 있는 것을 확인하였다. Fig. $3(\mathrm{c})$ 의 $1300^{\circ} \mathrm{C}$ 에서 하소한 분말에서는 Fig. 3(a), (b)에 비해서 안료 입자의 표면이 다소 곡면 형태를 가지는 것을 확인하였 다. 그러나 Fig. $3(\mathrm{~d})$ 의 $1500^{\circ} \mathrm{C}$ 에서 하소한 분말의 경우 응집 현상이 심하게 일어나, 낮은 온도에서 결정의 성장 을 촉진하기 위해 하소 온도를 낮춰 주거나 치환 원소의 고용 효율을 증가시키는 역할을 하는 광화제를 사용하여
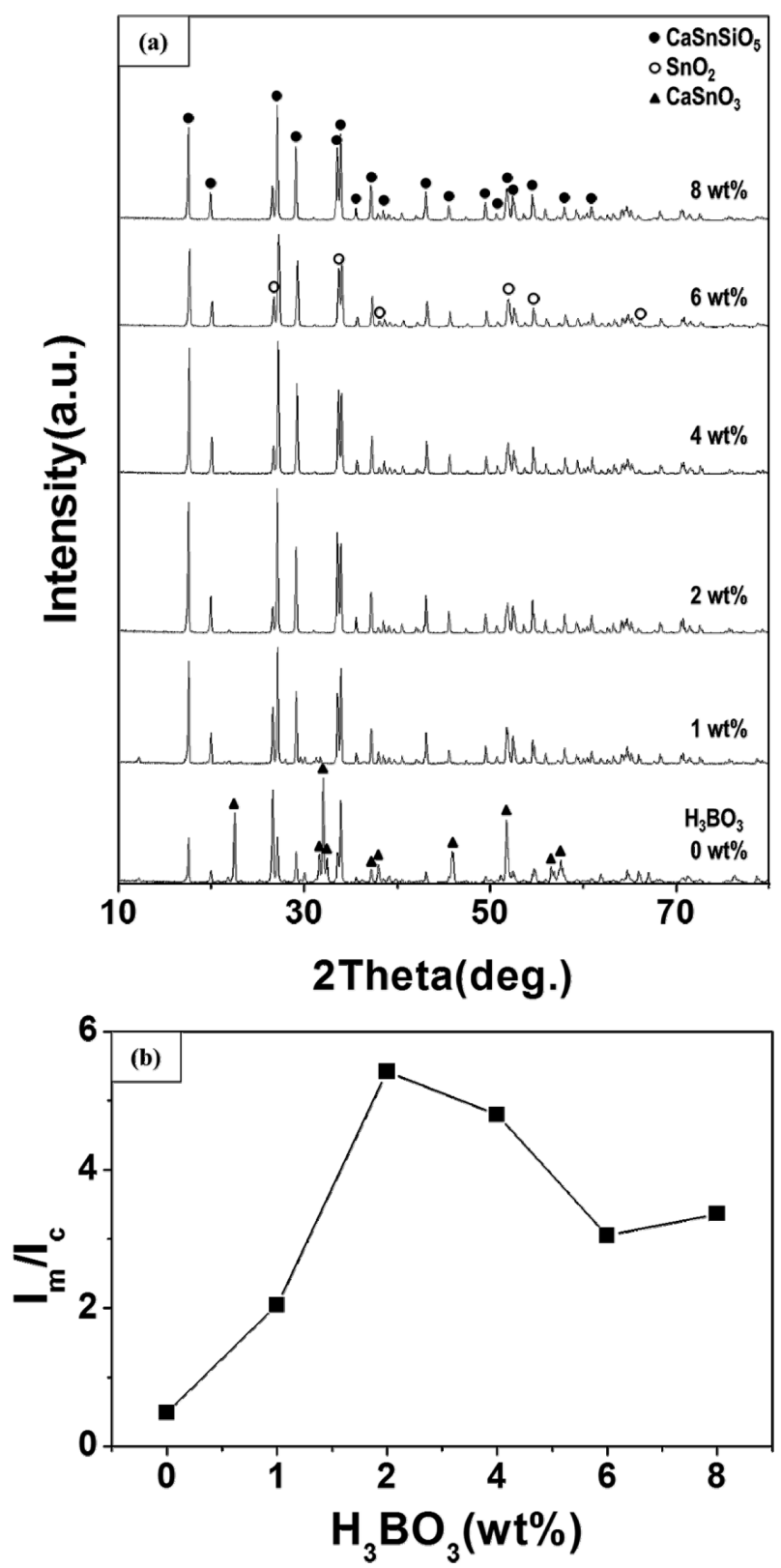

Fig. 4. (a) XRD patterns of $\mathrm{CaSnSiO}_{5}$ pigments synthesized with different amount of $\mathrm{H}_{3} \mathrm{BO}_{3}$ and (b) intensity ratio of XRD peaks corresponding to malayaite and cassiterite. 
$\mathrm{CaSnSiO}_{5}$ 합성을 진행하였다.

Fig. 4(a)는 광화제로 $\mathrm{H}_{3} \mathrm{BO}_{3}$ 를 $0 \sim 8 \mathrm{wt} \%$ 를 첨가하여 $1300^{\circ} \mathrm{C}$ 에서 하소한 분말의 $\mathrm{XRD}$ 분석 결과이다. 광화제 의 첨가량이 증가할수록 malayaite에 해당하는 $27.12^{\circ}$ 의 피크는 점점 증가하였으며, 반면에 cassiterite에 해당하 는 $26.61^{\circ}$ 의 피크는 감소하는 경향성을 확인할 수 있어 광화제가 malayaite의 성장에 큰 효과를 보이는 것으로 판단된다. Fig. 4(b)에 $\mathrm{H}_{3} \mathrm{BO}_{3}$ 첨가량에 따른 malayaite와 cassiterite의 비율을 정량적으로 분석하기 위해서 $27.12^{\circ}$ 피크(malayaite)와 $26.61^{\circ}$ 피크(cassiterite)의 intensity 비 율 $\left(\mathrm{I}_{\mathrm{m}} / \mathrm{I}_{\mathrm{c}}\right)$ 을 나타내었다. $\mathrm{H}_{3} \mathrm{BO}_{3}$ 첨가량에 따라 $2 \mathrm{wt} \%$ 까 지는 $\mathrm{I}_{\mathrm{m}} / \mathrm{I}_{\mathrm{c}}$ 값이 급격하게 증가하는 경향이 나타났으며, 그 이상 첨가 시 $\mathrm{I}_{\mathrm{m}} / \mathrm{I}_{\mathrm{c}}$ 값은 다소 감소하는 경향을 확인할 수 있었다.

Fig. 5는 $\mathrm{H}_{3} \mathrm{BO}_{3}$ 첨가량에 따른 미세구조 및 평균 입 도를 확인한 결과이다. $\mathrm{H}_{3} \mathrm{BO}_{3}$ 를 첨가하지 않은 경우에 는 Fig. 5(a)에서 볼 수 있듯이 입자들이 응집되어있는 것으로 관찰되며, $\mathrm{H}_{3} \mathrm{BO}_{3}$ 를 $2 \mathrm{wt} \%$ 첨가하였을 경우에는 (Fig. 5(b)) 약 수 크기의 입자들과 함께 일부 막대 형상의 입자도 형성됨을 확인할 수 있었다. Fig. $5(\mathrm{c})$ 의 $\mathrm{H}_{3} \mathrm{BO}_{3}$ 를 $4 \mathrm{wt} \%$ 첨가하여 하소한 분말은 Fig. 5(b)와 형상이 유사하나 입자 크기가 크게 증가하는 것을 확인할 수 있 었다. Fig. 5(d)는 $\mathrm{H}_{3} \mathrm{BO}_{3}$ 첨가량에 따른 평균 입자크기 를 레이저 회절 방식 입도 분석기를 통해 분석한 결과이 다. $\mathrm{H}_{3} \mathrm{BO}_{3}$ 첨가량이 $0 \sim 2 \mathrm{wt} \%$ 일때는 분말의 평균 입도 가 $10 \sim 25 \mu \mathrm{m}$ 로 나타났으나 $\mathrm{H}_{3} \mathrm{BO}_{3}$ 를 $4 \mathrm{wt} \%$ 와 $8 \mathrm{wt} \%$ 첨가하였을 경우 평균 입도는 각각 약 $70 \mu \mathrm{m}$ 와 $100 \mu \mathrm{m}$ 이상으로 크게 증가하는 것을 확인하였다.

위와 같이 하소 온도 및 $\mathrm{H}_{3} \mathrm{BO}_{3}$ 첨가량을 최적화하여
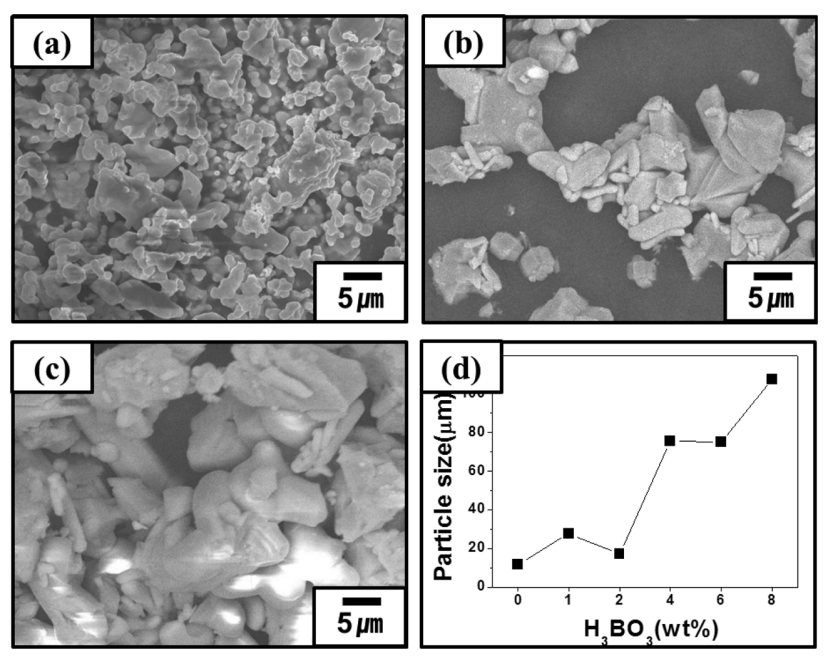

Fig. 5. SEM images of $\mathrm{CaSnSiO}_{5}$ pigments synthesized (a) without $\mathrm{H}_{3} \mathrm{BO}_{3}$, (b) with $2 \mathrm{wt} \% \mathrm{H}_{3} \mathrm{BO}_{3}$, (c) with $4 \mathrm{wt} \% \mathrm{H}_{3} \mathrm{BO}_{3}$ and (d) average particle size of $\mathrm{CaSnSiO}_{5}$ pigments synthesized with different amount of $\mathrm{H}_{3} \mathrm{BO}_{3}$. malayaite의 성장을 최적화하였으며, 추가적으로 잔존하는 cassiterite의 성장을 보다 억제하기 위해 $\mathrm{SnO}_{2}$ 첨가량을 비화학양론 조성비로 $1 \mathrm{~mol}$ 에서 $0.8 \mathrm{~mol}$ 까지 $0.5 \mathrm{~mol}$ 씩 감소시키면서 $\mathrm{CaSnSiO}_{5}$ 분말합성을 진행하였다. Fig. 6(a)는 $\mathrm{SnO}_{2}$ 의 첨가량에 따른 $\mathrm{XRD}$ 결과로 $\mathrm{H}_{3} \mathrm{BO}_{3}$ 첨가 량은 $2 \mathrm{wt} \%$ 이며 하소 온도는 $1300 \mu \mathrm{m}$ 이다. $\mathrm{SnO}_{2}$ 첨가 량이 $1 \mathrm{~mol}$ 에서 $0.9 \mathrm{~mol}$ 로 감소할 경우 cassiterite에 해 당하는 피크 $\left(26.61^{\circ}\right)$ 는 점점 감소하였으나 $0.9 \mathrm{~mol}$ 이하 로 첨가하여 하소한 분말에서는 cassiterite가 다시 성장 하는 경향을 보였다. Fig. 4(b)에서와 같이 $\mathrm{SnO}_{2}$ 첨가량 에 따른 malayaite와 cassiterite의 비율을 XRD 피크의 intensity비교를 통해 분석하였다. Fig. 6(b)와 같이 0.9
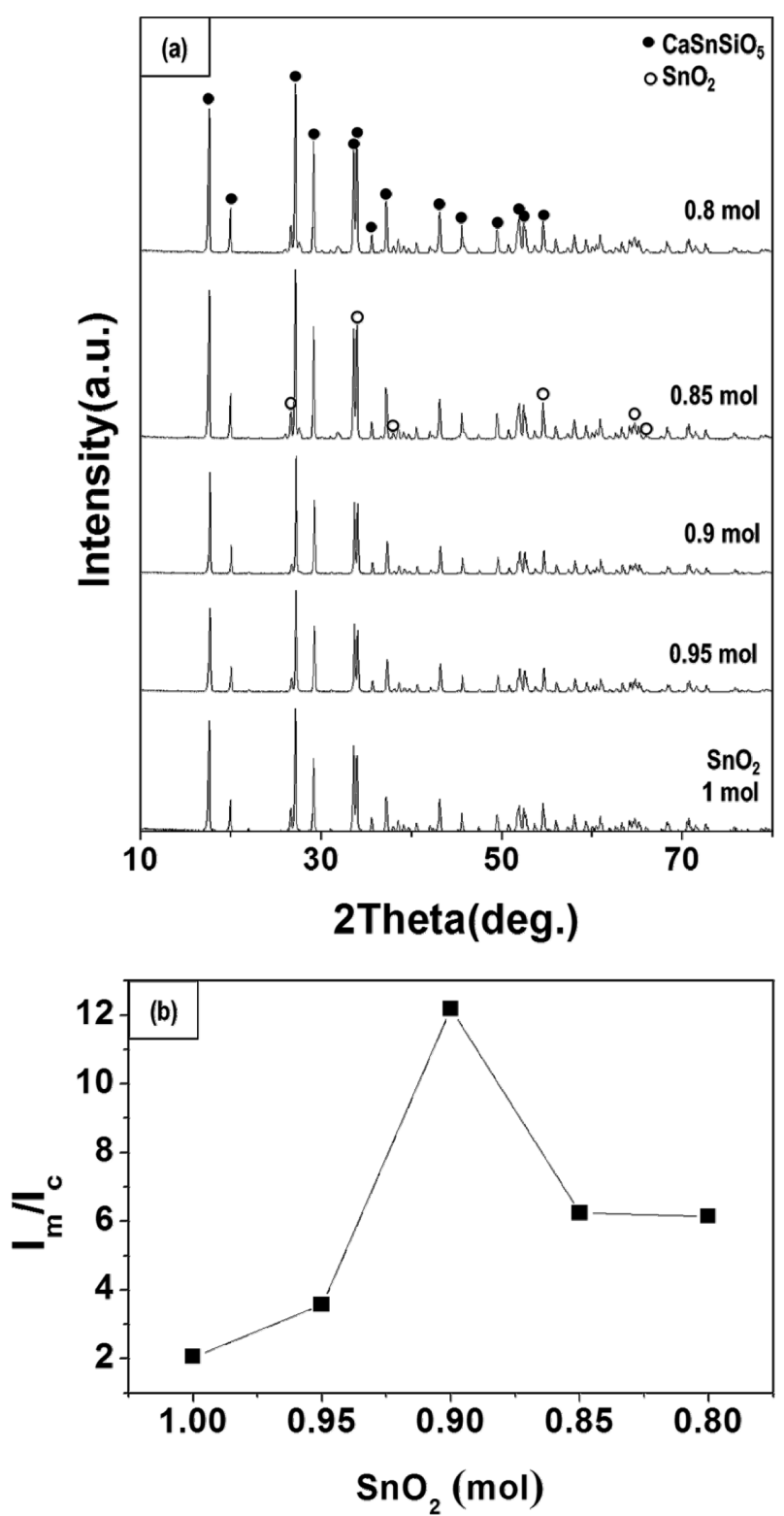

Fig. 6. (a) XRD patterns of $\mathrm{CaSnSiO}_{5}$ pigments synthesized with different amount of $\mathrm{SnO}_{2}$ and (b) intensity ratio of XRD peaks corresponding to malayaite and cassiterite. 


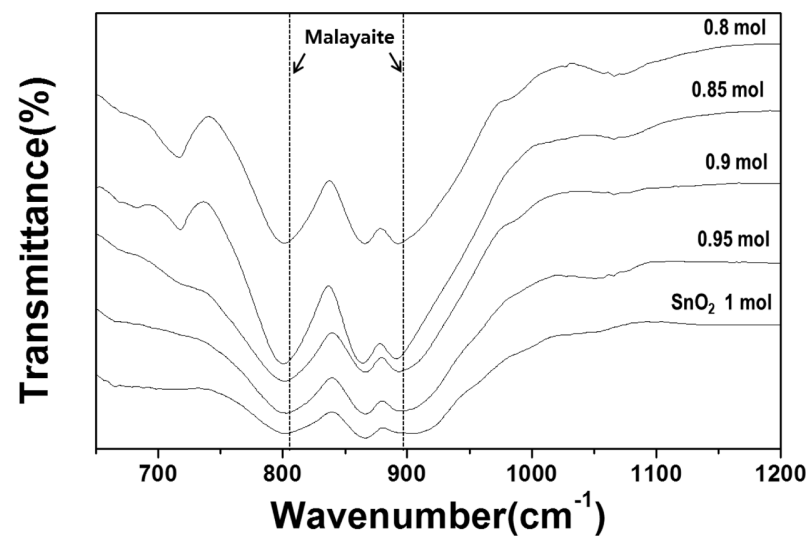

Fig. 7. FT-IR spectra of $\mathrm{CaSnSiO}_{5}$ pigments synthesized with different amount of $\mathrm{SnO}_{2}$.

$\mathrm{mol}$ 첨가한 $\mathrm{CaSn}_{0.9} \mathrm{SiO}_{5}$ 분말에서 가장 높은 $\mathrm{I}_{\mathrm{m}} / \mathrm{I}_{\mathrm{c}}$ 값을 확인할 수 있었다.

Fig. 7은 $\mathrm{SnO}_{2}$ 의 첨가량 감소에 따른 FT-IR 분석 결 과이다. $\mathrm{SnO}_{2}$ 첨가량이 감소함에 따라 malayaite의 흡수 밴드인 $807 \mathrm{~cm}^{-1}, 900 \mathrm{~cm}^{-1}$ 에서 특성 밴드가 증가하는 것을 확인할 수 있었으며 [7, 11], $\mathrm{SnO}_{2}$ 첨가량이 $0.9 \mathrm{~mol}$ 이하일 경우 Fig. 7(d), (f)와 같이 $1070 \mathrm{~cm}^{-1}$ 흡수 밴드 가 약간 성장하는 것을 확인할 수 있었다. $1070 \mathrm{~cm}^{-1}$ 흡 수 밴드는 $\mathrm{SiO}_{2}$ 흡수 밴드로 알려져 있는데[12], 이는 $\mathrm{SnO}_{2}$ 첨가량이 감소함에 따라 미반응된 잔존 $\mathrm{SiO}_{2}$ 때문 인 것으로 판단된다.

Fig. 8은 pink-red 발색을 위한 $\mathrm{Cr}$ 치환량에 따른 $\mathrm{CaCr}_{\mathrm{x}} \mathrm{Sn}_{0.9-\mathrm{x}} \mathrm{SiO}_{5}$ 무기안료의 $\mathrm{XRD}$ 분석 결과이다. $\mathrm{Cr}$ 을 0.01 에서 0.1 까지 치환한 무기안료의 경우 앞서 Fig. 6 의 결과와 같이 malayaite 단일 결정상이 잘 형성되는

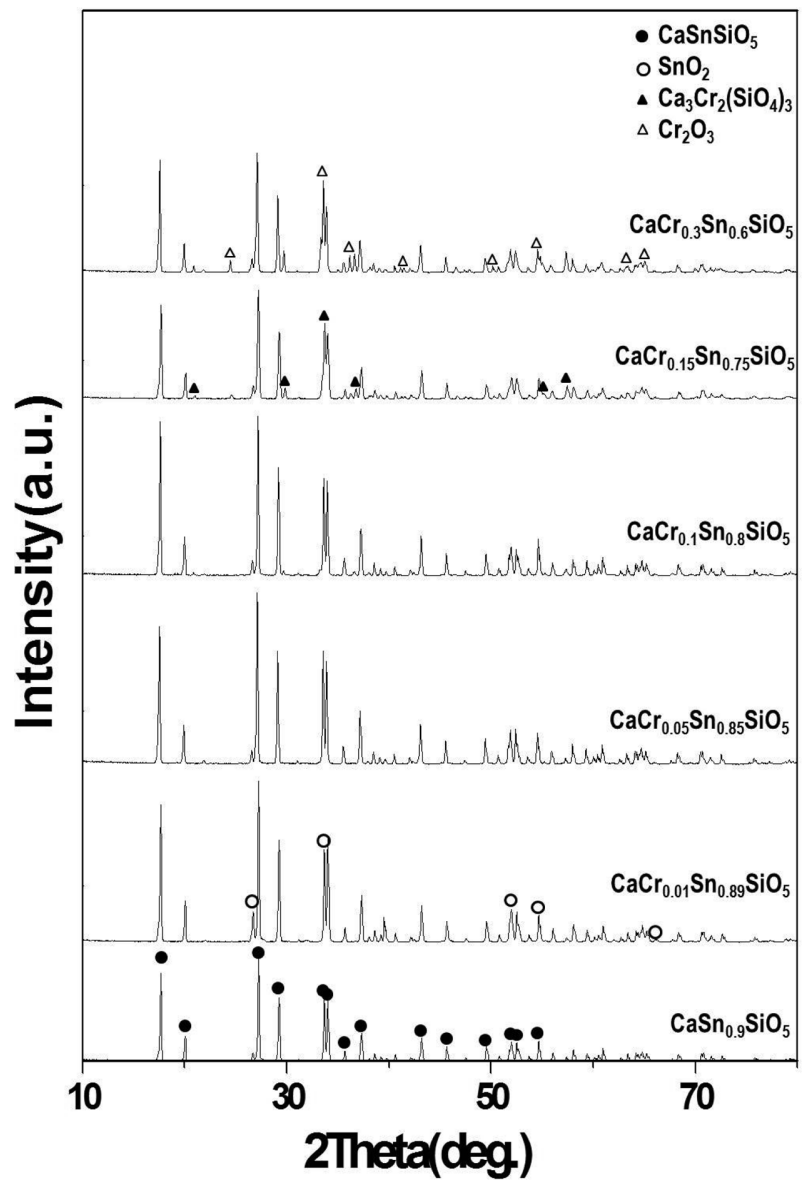

Fig. 8. XRD patterns of $\mathrm{CaCr}_{\mathrm{x}} \mathrm{Sn}_{0.9-\mathrm{x}} \mathrm{SiO}_{5}$ pigments $(\mathrm{x}=0$, $0.01,0.05,0.1,0.15,0.3)$.

것을 확인하였으나 $\mathrm{Cr}$ 치환량이 0.15 이상일 경우 Fig. 8(e)와 $8(\mathrm{f})$ 와 같이 $\mathrm{Ca}_{3} \mathrm{Cr}_{2}\left(\mathrm{SiO}_{4}\right)_{3}(\mathrm{Uvarovite})$ 와 $\mathrm{Cr}_{2} \mathrm{O}_{3}$
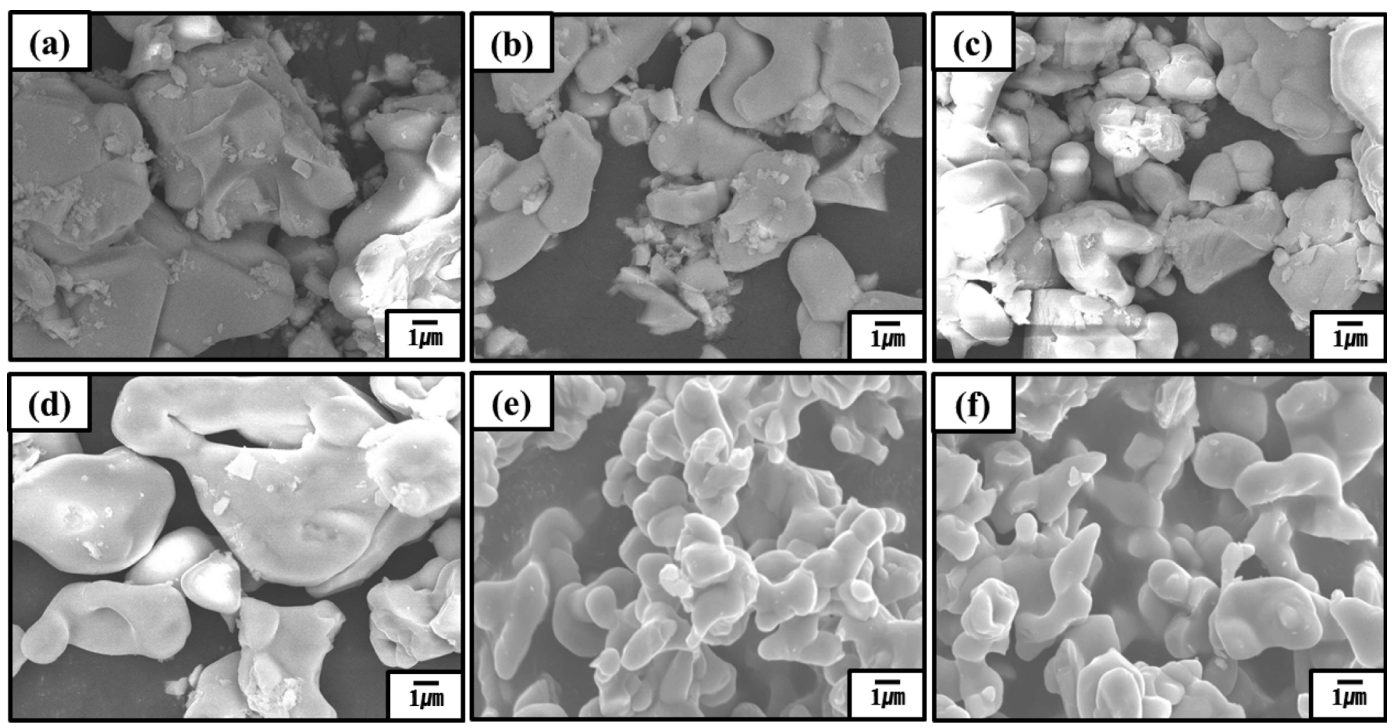

Fig. 9. SEM images of (a) $\mathrm{CaSn}_{0.9} \mathrm{SiO}_{5}$, (b) $\mathrm{Ca}_{0.01} \mathrm{Sn}_{0.89} \mathrm{SiO}_{5}$, (c) $\mathrm{Ca}_{0.05} \mathrm{Sn}_{0.85} \mathrm{SiO}_{5}$, (d) $\mathrm{Ca}_{0.1} \mathrm{Sn}_{0.8} \mathrm{SiO}_{5}$, (e) $\mathrm{Ca}_{0.15} \mathrm{Sn}_{0.75} \mathrm{SiO}_{5}$, (f) $\mathrm{Ca}_{0.3} \mathrm{Sn}_{0.6} \mathrm{SiO}_{5}$ pigments. 


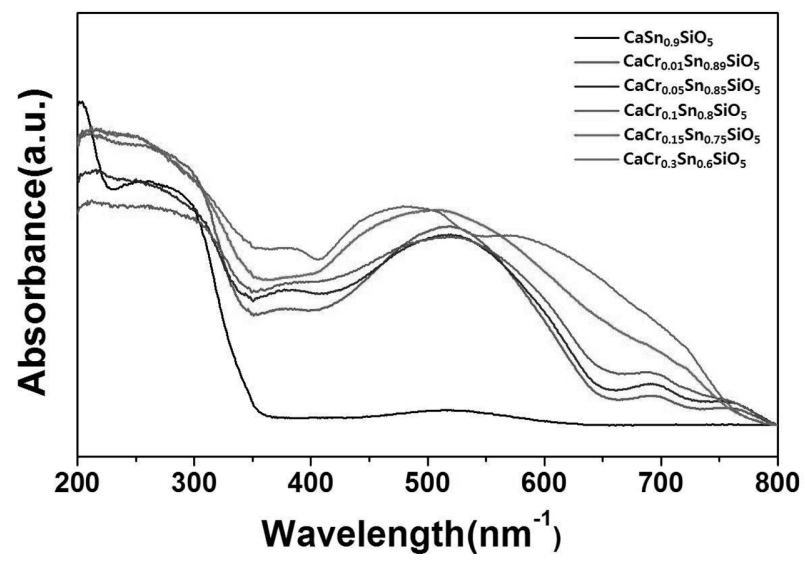

Fig. 10. Uv-vis. spectra of $\mathrm{CaCr}_{x} \mathrm{Sn}_{0.9-\mathrm{x}} \mathrm{SiO}_{5}$ pigments $(\mathrm{x}=0$, $0.01,0.05,0.1,0.15,0.3)$.

(Eskolaite)가 일부 형성되는 것을 확인할 수 있었다. Fig. 9는 $\mathrm{Cr}$ 치환량에 따른 $\mathrm{CaCr}_{\mathrm{x}} \mathrm{Sn}_{0.9-\mathrm{x}} \mathrm{SiO}_{5}$ 무기안료의 미세구조를 보여준다. Fig. 9(a) 9(d)의 $\mathrm{Cr}$ 치환량이 0에 서 0.1 일 경우에는 약 $10 \sim 30 \mu \mathrm{m}$ 의 입도를 가지는 입자 들을 관찰할 수 있었으나, $\mathrm{Cr}$ 치환량이 증가할수록 입도 가 감소하여 Fig. $9(\mathrm{e})$ 와 $9(\mathrm{f})$ 와 같이 $\mathrm{Cr}$ 치환량이 0.15 와 0.3 일 경우에는 약 $5 \sim 10 \mu \mathrm{m}$ 의 분포를 가진 입자들이 관찰되는 것을 알 수 있었다. 또한 $\mathrm{Cr}$ 의 치환량이 증가 함에 따라 입자 형상이 다소 구형으로 변해가는 것을 확 인할 수 있었는데 이는 출발 물질로 사용된 $\mathrm{Cr}_{2} \mathrm{O}_{3}$ 가 융 제 역할을 하여 입자들이 표면적을 줄이기 위해 둥근 형 태로 성장하는 것으로 사료된다[13].

$\mathrm{Cr}$ 치환량에 따른 $\mathrm{CaCr}_{\mathrm{X}} \mathrm{Sn}_{0.9-\mathrm{x}} \mathrm{SiO}_{5}$ 무기안료의 발색 파 장의 변화를 Uv-vis.로 분석한 결과를 Fig. 10에 나타내었 다. $\mathrm{Cr}$ 이 치환되지 않은 $\mathrm{CaSn}_{0.9} \mathrm{SiO}_{5}$ 무기안료에서는 흡수 밴드가 나타나지 않았으나, $\mathrm{Cr}$ 이 치환된 무기 안료에서
는 강한 $520 \mathrm{~nm}^{-1}$ 의 흡수 밴드를 보였다. $\mathrm{Ca}(\mathrm{Cr}, \mathrm{Sn}) \mathrm{SiO}_{5}$ 무기안료의 주 흡수 밴드는 $520 \mathrm{~nm}^{-1}$ 에서 나타나는 밴 드로 malayaite 결정 내의 $\mathrm{Cr}(\mathrm{IV})$ 의 이온결합에 의한 것 으로 알려져 있다[14, 15]. 또한 $\mathrm{Cr}$ 치환량이 증가함에 따라 $380 \mathrm{~nm}^{-1}$ 의 흡수 밴드가 성장하는 것을 확인할 수 있었는데 이는 $\mathrm{Ca}(\mathrm{Sn}, \mathrm{Cr}) \mathrm{SiO}_{5}$ 무기안료의 $\mathrm{Sn}$ 위치에 고 용되지 못하고 미반응된 $\mathrm{Cr}(\mathrm{III})$ 의 흡수 밴드이다 $[10,11]$.

Fig. 11은 $\mathrm{Cr}$ 치환량에 따른 $\mathrm{CaCr}_{\mathrm{x}} \mathrm{Sn}_{0.9-\mathrm{x}} \mathrm{SiO}_{5}$ 무기안 료의 광학적 이미지를 보여주고 있다. $\mathrm{Cr}$ 이 0.1 첨가된 Fig. 11(d)의 무기안료가 magenta에 가장 가까운 pink-red 를 발색하는 것을 볼 수 있으며 $\mathrm{Cr}$ 치환량이 증가함에 따라, $\mathrm{Cr}$ 이 $0.15,0.3$ 치환된 Fig. 11(e), (f) 시료의 경 우 갈색 계통의 색상을 발현하는 것을 확인하였다. 이는 Fig. 8(e), (f) 결과에서 확인된 $\mathrm{Ca}_{3} \mathrm{Cr}_{2}\left(\mathrm{SiO}_{4}\right)_{3}($ Uvarovite $)$ 와 $\mathrm{Cr}_{2} \mathrm{O}_{3}$ (Eskolaite)가 발색에 영향을 주는 것으로 생각 된다.

$\mathrm{CaCr}_{\mathrm{x}} \mathrm{Sn}_{0.9-\mathrm{x}} \mathrm{SiO}_{5}$ 무기안료의 $\mathrm{Cr}_{2} \mathrm{O}_{3}$ 치환량에 따른 색 도 변화를 관찰하기 위해 Table 1 에 CIE $\mathrm{L}^{*} \mathrm{a}^{*} \mathrm{~b}$ *의 값 을 나타내었다. CIE L*a*b* 색 공간에서 $\mathrm{L}$ 값의 경우 백색도를 의미하며, $\mathrm{L}$ 값이 0 이면 검은색, $\mathrm{L}$ 값이 100 이 면 흰색을 의미한다. $\mathrm{a}$ 값은 빨강과 초록색의 범위를 의 미 하는데, - 값은 초록색을 의미하며, + 값은 빨간색을 의미한다. $b$ 값은 - 값이면 파란색을 의미하고, + 값이면, 노란색을 의미한다. $\mathrm{CaCr}_{x} \mathrm{Sn}_{0.9-\mathrm{x}} \mathrm{SiO}_{5}$ 무기안료에서 $\mathrm{Cr}$ 첨가량이 증가함에 따라 $\mathrm{L}$ 값은 75.59 에서, $\mathrm{Cr}$ 을 0.01 첨가 시 45.63, 0.05 첨가 시 43.32, 0.1 첨가 시 20.19로 감소하는 경향을 보이다가, $\mathrm{Cr}$ 이 0.1 이상 첨가되면 다 소 증가하는 경향을 나타냈다. $\mathrm{a}$ 값의 경우에는 $\mathrm{Cr}$ 첨가 량의 증가와 함께 0.1 첨가까지는 증가하다가 그 이상에 서는 다시 감소하는 결과를 보이며, $\mathrm{b}$ 값의 경우 $\mathrm{Cr}$ 첨가
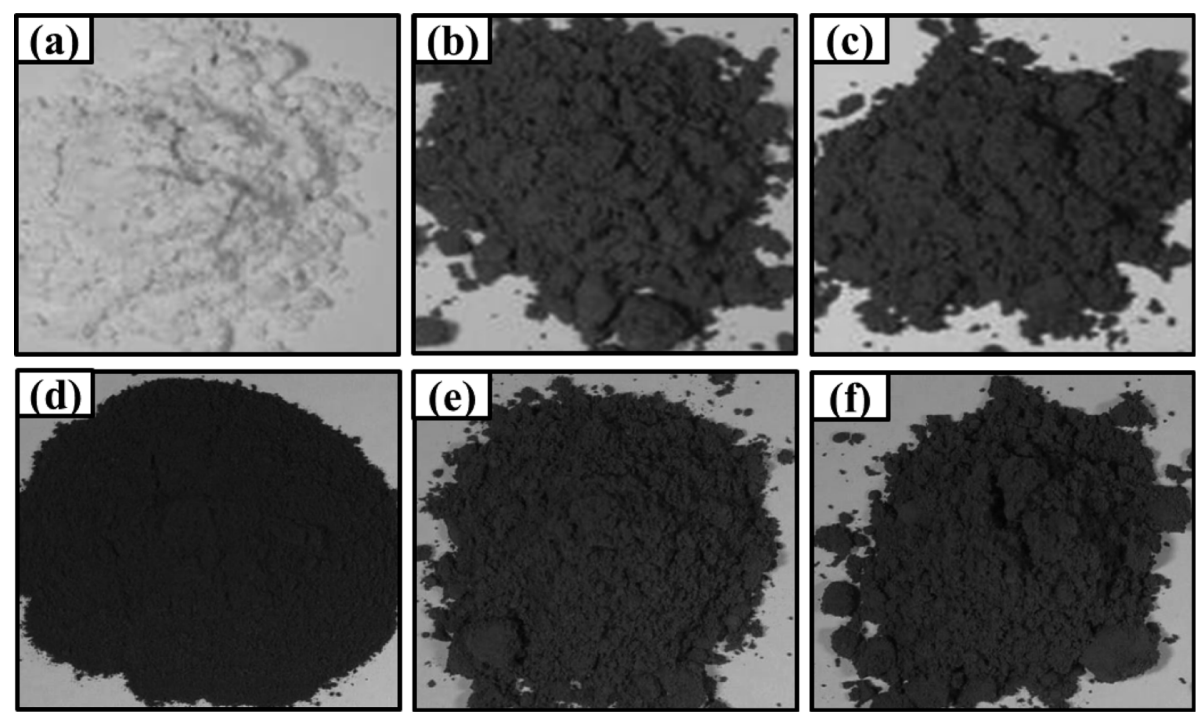

Fig. 11. Optical images of (a) $\mathrm{CaCrSn}_{0.9} \mathrm{SiO}_{5}$, (b) $\mathrm{CaCr}_{0.01} \mathrm{Sn}_{0.89} \mathrm{SiO}_{5}$, (c) $\mathrm{CaCr}_{0.05} \mathrm{Sn}_{0.85} \mathrm{SiO}_{5}$, (d) $\mathrm{CaCr}_{0.1} \mathrm{Sn}_{0.8} \mathrm{SiO}_{5}$, (e) $\mathrm{CaCr}_{0.15} \mathrm{Sn}_{0.75} \mathrm{SiO}_{5}$, (f) $\mathrm{CaCr}_{0.3} \mathrm{Sn}_{0.6} \mathrm{SiO}_{5}$ pigments. 
Table 1

CIE L*a*b* colourimetric parameters of $\mathrm{CaCr}_{\mathrm{x}} \mathrm{Sn}_{0.9-\mathrm{x}} \mathrm{SiO}_{5}$ ceramic pigments $(\mathrm{x}=0,0.01,0.05,0.1,0.15,0.3)$

\begin{tabular}{llll}
\hline & $\mathrm{L}^{*}$ & $\mathrm{a}^{*}$ & $\mathrm{~b}^{*}$ \\
\hline $\mathrm{CaSn}_{0.9} \mathrm{SiO}_{5}$ & 75.59 & 3.34 & 2.54 \\
$\mathrm{CaCr}_{0.01} \mathrm{Sn}_{0.89} \mathrm{SiO}_{5}$ & 45.63 & 11.03 & 2.38 \\
$\mathrm{CaCr}_{0.05} \mathrm{Sn}_{0.85} \mathrm{SiO}_{5}$ & 43.32 & 7.77 & 2.64 \\
$\mathrm{CaCr}_{0.1} \mathrm{Sn}_{0.8} \mathrm{SiO}_{5}$ & 20.19 & 13.35 & 6.9 \\
$\mathrm{CaCr}_{0.15} \mathrm{Sn}_{0.75} \mathrm{SiO}_{5}$ & 26.71 & 11.7 & 4.96 \\
$\mathrm{CaCr}_{0.3} \mathrm{Sn}_{0.6} \mathrm{SiO}_{5}$ & 29.51 & 5.83 & 9.13 \\
\hline
\end{tabular}

량의 증가와 함께 서서히 증가하는 경향이 확인되었다.

\section{4. 결 론}

디지털 컬러용 pink-red 발색 $\mathrm{CaCr}_{x} \mathrm{Sn}_{0.9-x} \mathrm{SiO}_{5}$ 세라믹 안료의 최적 합성 조건을 도출하고 합성 조건에 따른 발 색거동을 분석하였다. 무기 안료 입자의 응집 현상을 최소 화하기 위해 광화제인 $\mathrm{H}_{3} \mathrm{BO}_{3}$ 를 첨가하여 $1300^{\circ} \mathrm{C}$ 에서 열 처리를 진행한 결과 pink-red 발색을 위한 $\mathrm{Ca}(\mathrm{Sn}, \mathrm{Cr}) \mathrm{SiO}_{5}$ (malayaite)를 성장시킬 수 있었다. 또한 $\mathrm{Ca}(\mathrm{Sn}, \mathrm{Cr}) \mathrm{SiO}_{5}$ 무기안료의 합성 과정 중 malayaite와 함께 생성되는 $\mathrm{SnO}_{2}$ (cassiterite)의 생성을 억제하기 위해 $\mathrm{SnO}_{2}$ 함량을 비화학양론 조성비로 감소시키면서 합성한 결과 $\mathrm{SnO}_{2}$ 가 $0.9 \mathrm{~mol}$ 첨가되었을 때 cassiterite를 최소화시키면서 $\mathrm{Ca}(\mathrm{Sn}, \mathrm{Cr}) \mathrm{SiO}_{5}$ 무기 안료를 합성할 수 있었다. Pink-red 발색을 위한 $\mathrm{Cr}$ 치환량에 따른 발색 거동을 $\mathrm{Uv}$-vis.로 분석한 결과 malayaite의 $\mathrm{Cr}(\mathrm{IV})$ 특성 밴드 $\left(520 \mathrm{~nm}^{-1}\right)$ 는 $\mathrm{Cr}$ 첨가량에 따라 큰 변화가 없었으나, 미 반응된 $\mathrm{Cr}(\mathrm{III})$ 의 $380 \mathrm{~nm}^{-1}$ 특성 밴드에서의 변화가 발색에 영향을 끼 치는 것으로 판단된다. $\mathrm{CIE} \mathrm{L}^{*} \mathrm{a} * \mathrm{~b} *$ 측정결과 $\mathrm{Cr}$ 첨가 량이 증가할수록 $\mathrm{L}$ 값은 점점 감소하다가 $\mathrm{Cr}$ 첨가량이 0.1 이상일 경우 다소 증가하였고, $\mathrm{a}$ 값은 $\mathrm{Cr}$ 첨가량이 0.1 에서 가장 높게 나타났으며, $\mathrm{b}$ 값은 $\mathrm{Cr}$ 첨가량의 커질 수록 함께 증가하는 경향을 확인하였다.

\section{감사의 글}

본 논문은 미래창조과학부 - 산업통상지원부가 공동지 원한 '나노융합 2020 사업'으로 지원된 연구결과입니다잉 크젯프린팅 포셀린 제품용 고화도 나노세라믹 발색잉크 제조].

\section{References}

[ 1 ] D. Gardini, M. Dondi, A.L. Costa, F. Matteucci, M.
Blosi and C. Galassi, "Nano-sized ceramic inks for drop-on-demand ink-jet printing in quadrichromy", J. Nanosci. Nanotechnol. 8 (2008) 1979.

[2] I. Fasaki, K. Siamos, M. Arin, P. Lommens, I. VanDriessche, S.C. Hopkins, B.A. Glowacki and I. Arabazis, "Ultrasound assisted preparation of stable waterbased nanocrystalline $\mathrm{TiO}_{2}$ suspensions for photocatalytic applications of inkjet-printed films", Appl. Catal., A: General. 60 (2012) 411.

[3 ] P.M.T. Cavalcante, M. Dondi, G. Guarini, M. Raimondo and G. Baldi, "Colour performance of ceramic nano-pigments", Dyes Pigm. 80 (2009) 226.

[4] A. Doménech, F.J. Torres, E.R. de Sola and J. Alarcón, "Electrochemical detection of high oxidation states of chromium (IV and V) in chromium-doped cassiterite and tin-sphene ceramic pigmenting systems", Eur. J. Inorg. Chem. 2006 (2006) 638.

[5] B. Julin, H. Beltrn, E. Cordoncillo, P. Escribano, J.V. Folgado, M.V. Regi and R.P.d. Real, "A study of the method of synthesis and chromatic properties of the Cr$\mathrm{SnO}_{2}$ pigment", Eur. J. Inorg. Chem. 10 (2002) 2694.

[6] A.M. Heyns and P.M. Harden, "Evidence for the existence of $\mathrm{Cr}(\mathrm{IV})$ in chromium-doped malayaite $\mathrm{Cr}^{4+}$ : $\mathrm{CaSnOSiO}_{4}$ : a resonance raman study", J. Phys. Chem. Solids. 60 (1998) 277.

[ 7 ] G. Costa, M.J. Ribeiro, J.A. Labrincha, M. Dondi, F. Matteucci and G. Cruciani, "Malayaite ceramic pigments prepared with galvanic sludge", Dyes Pigm. 78 (2008) 157.

[ 8 ] J.W. Moon, Y.H. Song, W.J. Park and D.H. Yoon, "Luminescence characterization of $\mathrm{Eu}^{3+}$ and $\mathrm{Bi}^{3+}$ codoped in $\mathrm{Y}_{2} \mathrm{SiO}_{5}$ red emitting phosphor by solid state reaction method", J. Korean Cryst. Growth. Cryst. Technol. 19 (2009) 15.

[9] C.S. Kim, "Electrical conductivity of olivine type $\mathrm{LiFe}_{0.965} \mathrm{Cr}_{0.03} \mathrm{~B}_{0.005} \mathrm{PO}_{4}$ and $\mathrm{LiFe}_{0.965} \mathrm{Cr}_{0.03} \mathrm{Al}_{0.005} \mathrm{PO}_{4}$ powders", J. Korean Cryst. Growth. Cryst. Technol. 20 (2010) 141.

[10] F.J. Berry, N. Costanatini and L.E. Smart, "Synthesis of chromium-containing from pigment chromium recovered from leather waste", Waste Manage. 22 (2002) 761.

[11] N.T. McDevitt and W.L. Baun, "Infrared absorption study of metal oxides in the low frequency region (700 $240 \mathrm{~cm}^{-1}$ )", Spectrochim. Acta 20 (1964) 799.

[12] H. Zhang, X. Lei, Z. Su and P. Liu "A novel method of surface-iniate atom transfer radical polymerization of styrene from silica nanoparticles for preparation of monodispersed core-shell hybrid nanospheres", J. polym. Res. 14 (2007) 253.

[13] P. Rado, "An introduction to the technology of pottery”, Pergamon Press (1969) 15-685.

[14] E. Lopez, G. Monzonis and A. Navarro, "Cr-SnO $-\mathrm{CaO}-$ $\mathrm{SiO}_{2}$-based ceramic pigments", Am. Ceram. Soc. Bull. 63 (1984) 1492.

[15] I.R. Mulholland, "Malayaite and tin-bearing garnet from a skarn at Gumble, NSW, Australia", Minreral. Mag. 48 (1984) 27. 